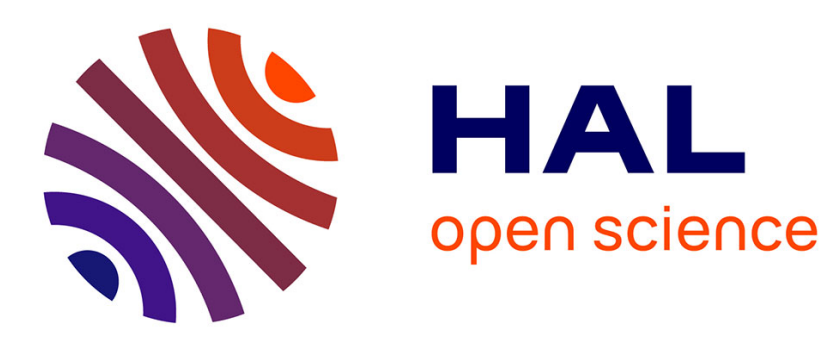

\title{
Direct synthesis of L10 FePt nanoparticles within carbon nanotubes by wet chemical procedure
}

A Capobianchi, S Laureti, D Fiorani, S Foglia, E Palange

\section{To cite this version:}

A Capobianchi, S Laureti, D Fiorani, S Foglia, E Palange. Direct synthesis of L10 FePt nanoparticles within carbon nanotubes by wet chemical procedure. Journal of Physics D: Applied Physics, 2010, 43 (47), pp.474013. 10.1088/0022-3727/43/47/474013 . hal-00597840

\section{HAL Id: hal-00597840 \\ https://hal.science/hal-00597840}

Submitted on 2 Jun 2011

HAL is a multi-disciplinary open access archive for the deposit and dissemination of scientific research documents, whether they are published or not. The documents may come from teaching and research institutions in France or abroad, or from public or private research centers.
L'archive ouverte pluridisciplinaire HAL, est destinée au dépôt et à la diffusion de documents scientifiques de niveau recherche, publiés ou non, émanant des établissements d'enseignement et de recherche français ou étrangers, des laboratoires publics ou privés. 


\title{
Direct Synthesis of $\mathrm{L1}_{0} \mathrm{FePt}$ nanoparticles within Carbon Nanotubes by Wet Chemical Procedure
}

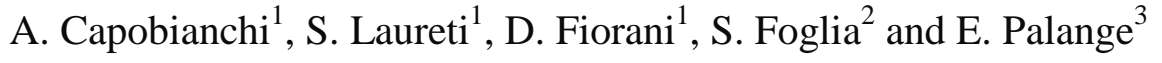 \\ 1.Consiglio Nazionale delle Ricerche (CNR), Istituto di Struttura della Materia \\ (ISM), Rome, Italy \\ 2.Consiglio Nazionale delle Ricerche (CNR), Istituto di Fotonica e Nanotecnologie, \\ Rome, Italy \\ 3.Università degli Studi dell'Aquila, Dipartimento di Ingegneria Elettrica e \\ dell'Informazione, L'Aquila, Italy \\ aldo.capobianchi@ism.cnr.it
}

\begin{abstract}
This paper reports on the low temperature synthesis of $\mathrm{L}_{0}$ iron-platinum $(\mathrm{FePt})$ particles within Multi Wall Carbon Nanotubes using a novel wet chemical method that allows the filling of the nanotube cavity keeping clear its external wall. In the proposed procedure, nanotubes are filled with a precursor salt of hexaaquairon(II) hexachloroplatinate, $\left(\left[\mathrm{Fe}\left(\mathrm{H}_{2} \mathrm{O}\right)_{6}\right]\left[\mathrm{PtCl}_{6}\right]\right)$ and nanoparticles of the magnetically hard phase are directly obtained by heating at $400^{\circ} \mathrm{C}$ in a reductive atmosphere. The advantage of such precursor, allowing to obtain at low temperature the $\mathrm{L} 1_{0}$ phase without passing trough the soft fcc phase, is due to its structure, where the Fe and Pt atoms are arranged in alternating planes, like in the fct FePt structure. Morphological, structural and magnetic properties of the filled nanotubes have been investigated by transmission electron microscopy, X-ray diffraction and magnetization measurements. The results show the coexistence of nanoparticles in the superparamagnetic and blocked state, depending on the temperature, due to the particle size distribution.
\end{abstract}




\section{Introduction}

FePt alloys in the chemically ordered face-centered tetragonal (fct) $\left(\mathrm{L}_{0}\right)$ are materials of great interest for perpendicular recording media, as they have a large uniaxial magneto-crystalline anisotropy [1] (magnetic anisotropic constant, $K_{u}=7 \times 10^{6} \mathrm{~J} / \mathrm{m}^{3}$ ), making particles so small as 2-3 nm magnetically stable at room temperature. Generally, FePt nanoparticles are obtained in the chemically disordered face-centered cubic (fcc) phase and a post-growth annealing treatment at around $600{ }^{\circ} \mathrm{C}$ is necessary to induce the transition to the chemically ordered face-centered tetragonal (fct) phase $\left(\mathrm{L}_{0}\right)$. Organic precursors are commonly used for the synthesis, e.g. FePt nanoparticles in fcc phase are synthesized by reduction of mixed metal salts (i.e., $\mathrm{Fe}(\mathrm{CO})_{5}$ and $\left.\mathrm{Pt}(\mathrm{acac})_{2}\right)$, in the presence of a long chain carboxylic acid and primary amines in organic solvent [2]. Recently, we reported [3,4] a new chemical strategy for the direct synthesis of FePt alloy starting from a polycrystalline salt of complex hexaaquairon(II) hexachloroplatinate $\left(\left[\mathrm{Fe}\left(\mathrm{H}_{2} \mathrm{O}\right)_{6}\right]\left[\mathrm{PtCl}_{6}\right]\right)$, in which $\mathrm{Fe}$ and $\mathrm{Pt}$ atoms are arranged on alternating planes like in the fct $\mathrm{FePt}$ structure. The reduction of such compound by $5 \% \mathrm{H}_{2}$ and $95 \%$ Ar at $400{ }^{\circ} \mathrm{C}$ leads directly to the highly ordered $\mathrm{L} 1_{0}$ phase.

In this paper we report on the preparation of $\mathrm{FePt} \mathrm{L}_{0}$ nanoparticles within multi wall carbon nanotubes (MWCNTs) using the above reported synthesis method. The encapsulation of organic and inorganic materials inside carbon nanotubes (CNTs) has attracted a great interest for the capability to modify and design the physical properties of composite materials at nanometric scale in a host medium with high surface area and unique mechanical an electrical properties. This has opened the way to a variety of applications in many scientific and technological fields, e.g. in polymer science [6], catalysis [8], nanoelectronics [10], photovoltaic devices [9], hydrogen storage [7]. In particular, CNTs filled with magnetic nanoparticles are of great interest for magnetic recording media [13], in biomedicine for drug delivering [14] and for tips in magnetic force microscopy. Recently, we reported a new patented strategy to fill the CNTs cavities $[15,16]$. In this work, such strategy is applied to the filling with $\mathrm{L}_{0}$ FePt nanoparticles, directly synthesized 
without passing through the fcc phase. In a preliminary work [17], the synthesis of FePt in $\mathrm{L}_{0}$ phase inside MWCNTs has been obtained by mixing the nanotubes in a starting water solution of two precursors salts and then heating at $700^{\circ} \mathrm{C}$ in a reductive atmosphere. In the present paper, the same product is obtained by using a unique salt water solution precursor and reducing the transition temperature at $400{ }^{\circ} \mathrm{C}$. The morphological, microstructural and magnetic characterization of the FePt@MWCNTs nanocomposite is reported.

\section{Experimental}

The MWCNTs used in this study, supplied by Nanocyl S.A. (Namur, Belgium), were grown by carbon catalytic vapor deposition technique. The wet chemical method used to fill the MWCNTs is a patented technique reported in detail in a previous work for the encapsulation of $\mathrm{CdS}$ crystal nanoclusters in MWCNTs [15-17]. MWCNTs were first opened at tips with nitric acid at $140^{\circ} \mathrm{C}$, washed and dried. Then, a starting solution of $\left[\mathrm{Fe}\left(\mathrm{H}_{2} \mathrm{O}\right)_{6}\right]\left[\mathrm{PtCl}_{6}\right]$ salt at two different concentrations $(0.1 \mathrm{M}$ and $0.01 \mathrm{M})$ was used to fill the MWCNT cavity following a two step procedure. First, the opened MWCNTs was mixed in the aqueous solution of $\left[\mathrm{Fe}\left(\mathrm{H}_{2} \mathrm{O}\right)_{6}\right]\left[\mathrm{PtCl}_{6}\right]$ salt at room temperature under vacuum $\left(10^{-2} \mathrm{mmHg}\right)$. The filling of the nanotubes occurs just by capillarity, when the atmospheric pressure is quickly restored by flowing nitrogen gas and the resulting high difference in pressure between the internal and external nanotube wall induces the solution penetration into the MWCNT cavity. After few minutes of ultrasonic treatment and successive stirring for a day, the mixture was frozen in a cold bath at a temperature just below the solution freezing point. In these conditions, the solvent was sublimated at a pressure close to $10^{-2} \mathrm{mmHg}$ for 2 days. At the end of this process, the samples were constituted of $\left[\mathrm{Fe}\left(\mathrm{H}_{2} \mathrm{O}\right)_{6}\right]\left[\mathrm{PtCl}_{6}\right]$ salt clusters encapsulated inside the MWCNTs and deposited on the external MWCNTs surface. In the second step, the solid mixture of filled MWCNTs and salt clusters were treated with an organic solvent, such as benzene, in which the $\left[\mathrm{Fe}\left(\mathrm{H}_{2} \mathrm{O}\right)_{6}\right]\left[\mathrm{PtCl}_{6}\right]$ salt is not soluble. The solvent penetrates through the MWCNTs opened tips by capillarity protecting the filling material from the washing solvent that was added right after. 
The washing solvent must be, at the same time, immiscible with benzene and able to dissolve $\left[\mathrm{Fe}\left(\mathrm{H}_{2} \mathrm{O}\right)_{6}\right]\left[\mathrm{PtCl}_{6}\right]$ salt. Thus, as solvent we used water that cannot enter into the tubes because of either the relatively high surface tension at the water/benzene interface and the small area of the MWCNT ends. As a consequence, benzene protects from water the salts clusters located inside the MWCNTs, while the other ones attached to the MWCNT external surface are in contact with both benzene and water. For the well known phase distribution process, the water soluble salts fasten on the external MWCNT surface are extracted by water and washed away. At the end of this procedure, the $\left[\mathrm{Fe}\left(\mathrm{H}_{2} \mathrm{O}\right)_{6}\right]\left[\mathrm{PtCl}_{6}\right]$ clusters are present mainly inside the MWCNTs. In order to transform the $\left[\mathrm{Fe}\left(\mathrm{H}_{2} \mathrm{O}\right)_{6}\right]\left[\mathrm{PtCl}_{6}\right]$ salt into $\mathrm{FePt} \mathrm{L1} 1_{0}$ alloy [4], the $\left(\left[\mathrm{Fe}\left(\mathrm{H}_{2} \mathrm{O}\right)_{6}\right]\left[\mathrm{PtCl}_{6}\right]\right) @ \mathrm{MWCNTs}$ were heated, with a rate increase of $5{ }^{\circ} \mathrm{C} / \mathrm{min}$, up to $400{ }^{\circ} \mathrm{C}$ in a reductive atmosphere of $\mathrm{H}_{2} 5 \%$ and Ar $95 \%$. The reaction takes place in more steps during the temperature increasing, and the complete chemical reaction is:

$$
\left[\mathrm{Fe}\left(\mathrm{H}_{2} \mathrm{O}\right)_{6}\right]\left[\mathrm{PtCl}_{6}\right]+3 \mathrm{H}_{2} \rightarrow \mathrm{FePt}+6 \mathrm{HCl}+6 \mathrm{H}_{2} \mathrm{O}
$$

The morphological characterization was performed by using a transmission electron microscope (TEM) Philips CM200 (thermoionic gun and acceleration voltage of $200 \mathrm{kV}$ ). The carbon nanotubes were observed by placing the specimens on high resolution Agar S160 carbon film 200 Mesh Cu grids.

The structural characterization was performed by X-ray diffraction (XRD) measurements by using a Seifert XRD $3000 \mathrm{P}$ powder diffractometer, using $\mathrm{Cu}$ Ka radiation $(\lambda=0.15418 \mathrm{~nm})$.

The magnetic measurements were carried out at $\mathrm{T}=300 \mathrm{~K}$ and at $\mathrm{T}=5 \mathrm{~K}$ by means of a commercial SQUID magnetometer (maximum magnetic field $\mathrm{H}_{\max }=55 \mathrm{kOe}$ ).

\section{Results and discussion}

In the synthesis of $\mathrm{L1}_{0} \mathrm{MePt}$ alloys $(\mathrm{Me}=\mathrm{Co}, \mathrm{Fe})$ usually reported in the literature, a high temperature treatment [18] is necessary in order to transform the obtained chemically disordered fcc structure into the fct phase $\left(\mathrm{L}_{0}\right)$. In our case, the direct formation of the $\mathrm{L}_{0}$ phase at low 
temperature $\left(400{ }^{\circ} \mathrm{C}\right)$ is due to the peculiar atomic arrangement of the precursor salt, whose structure is reported in ref [3]. A view of the crystal packing is shown in Figure 1, with octahedral representing $\left[\mathrm{PtCl}_{6}\right]^{2-}$ and $\left[\mathrm{Fe}\left(\mathrm{H}_{2} \mathrm{O}\right)_{6}\right]^{2+}$ ions, linked together through a network of hydrogen bonds. Two different sets of alternating Fe and Pt atomic planes can be distinguished along the [001] and [011] directions, respectively.

In Figure 2, the transmission electron microscopy (TEM) images of the filled FePt@MWCNTs are reported for two concentrations. It is shown that FePt nanoparticles are located only inside the nanotubes and that the external nanotube walls are clean. The average nanoparticle size is related to the initial salt solution concentration, resulting in a larger size distribution (between 1 and $10 \mathrm{~nm}$ ) for the $0.1 \mathrm{M}$ concentration. For the $0.01 \mathrm{M}$ concentration the particle size is between 1 and $3 \mathrm{~nm}$. The powder X-Ray diffraction (XRD) pattern of the FePt-filled MWCNTs prepared from the concentrated salt solution is reported in Figure 3. In the inset, the XRD pattern of empty and opened MWCNTs is also reported, showing the typical reflections reported in the literature [19]. The (002) reflection occurs at $2 \theta=25.823^{\circ}$, corresponding to an interlayer distance of $0.343 \mathrm{~nm}$. This confirms that the MWCNT structure was not modified by the chemical opening procedure. The XRD pattern of FePt-filled nanotubes, in particular the presence and the positions of the (001), (110), (111), (201), (112) reflections and the splitting of the (200), (002), (220) and (202) reflections, provides evidence of the formation of the L10 phase. Applying the Scherrer's formula to the XRD peaks, an average particle size of $4.3 \mathrm{~nm}$ is obtained, consistent with the CNTs diameter and in agreement with the results of TEM measurements.

The magnetic properties of the FePt@MWCNTs were investigated by measuring hysteresis cycles at $300 \mathrm{~K}$ and $5 \mathrm{~K}$. First we measured the hysteresis loop of empty and open MWCNTs. In Figure 4, the loop at $5 \mathrm{~K}$ is reported. The saturation magnetization is $\mathrm{M}_{\mathrm{s}}=0.4 \mathrm{emu} / \mathrm{g}$ and the coercive field $\mathrm{H}_{\mathrm{c}}$ $=1.2 \mathrm{kOe}$ ). The observed behaviour is due to the presence of ferromagnetic metallic impurities coming from residual nanoparticles of catalysts used in the preparation of the CNTs, not completely 
removed by nitric acid during the opening procedure. Such impurities are commonly found in CNTs.

The hysteresis loops for the nanotubes filled with FePt particles are reported in Figure 5 for the sample obtained starting from a $0.1 \mathrm{M}$ solution. The cycles show the presence of two contributions to the magnetization. At $5 \mathrm{~K}\left(\mathrm{M}_{\mathrm{s}}=2.74 \mathrm{emu} / \mathrm{g}\right)$, one contribution, responsible for the high anisotropy field (the cycle is not closed at $5 \mathrm{~K})$ and the large measured coercive field $\left(\mathrm{H}_{\mathrm{c}}=20 \mathrm{kOe}\right.$ at $5 \mathrm{~K}$; the actual value should be even larger), is attributed to the hard ferromagnetic $\mathrm{FePt} \mathrm{L}_{0}$ particles in the blocked state. A second contribution, responsible for the rapid variation of the magnetization at low fields, is due to a softer magnetic component, corresponding to the ferromagnetic metallic impurities coming from the growth of carbon nanotubes. In principle, the presence of a small fraction of soft ferromagnetic fcc FePt particles, coming from a not completed salt crystallization and not detected by X-ray diffraction, contributing to the low field behaviour of the magnetization, cannot be excluded. At $300 \mathrm{~K}, \mathrm{H}_{\mathrm{c}}=5 \mathrm{kOe}$ and $\mathrm{M}_{\mathrm{s}}=1.9 \mathrm{emu} / \mathrm{g}$. The low coercive field suggests that a fraction of FePt nanoparticles moved to a superparamagnetic state with increasing temperature. The high field irreversibility indicates that a fraction of still blocked FePt $\mathrm{L}_{0}$ nanoparticles is still present at room temperature. Such coexistence of blocked and superparamagnetic particles is coherent with the temperature dependence of the low field magnetization (Figure 6), measure after zero field cooling (ZFC) field cooling (FC), indicating a large distribution of particle size. The observed behaviour indicates a quite large distribution of blocking temperature.

In Figure 7, the hysteresis loops of the sample prepared starting from a $0.01 \mathrm{M}$ salt solution is reported. For this diluted sample, the contribution of the soft component to the magnetization is much more important. At $5 \mathrm{~K}, \mathrm{Hc}=1.3 \mathrm{kOe}$ and $\mathrm{M}_{\mathrm{s}}=0.5 \mathrm{emu} / \mathrm{g}$. Although these values are very close to those observed for the empty MWCNTs, the high field irreversibility is a clear indication of the presence of a fraction of the $\mathrm{L} 1_{0}$ hard phase even at room temperature. 


\section{Conclusions}

In this paper, the filling of MWCNTs with $\mathrm{L}_{0} \mathrm{FePt}$ nanoparticles, directly synthesized at $400{ }^{\circ} \mathrm{C}$ starting from a salt of the layered precursor hexaaquairon(II) hexachloroplatinate, $\left(\left[\mathrm{Fe}\left(\mathrm{H}_{2} \mathrm{O}\right)_{6}\right]\left[\mathrm{PtCl}_{6}\right]\right)$, is reported. The FePt nanoparticles encapsulation into the MWCNTs was achieved by using a wet chemical method that allows to introduce the particles within the MWCNT maintaining the external wall free of particles. The hysteresis cycles, measured at $5 \mathrm{~K}$ and at $300 \mathrm{~K}$, show the characteristics of the high anisotropy $\mathrm{L} 1_{0}$ phase (high coercivity, high field irreversibility). Due to the particle size distribution, at room temperature there is a coexistence of magnetic nanoparticles in the blocked and superparamagnetic state.

A low solution concentration was used in order to obtain the FePt $\mathrm{L} 1_{0}$ nanoparticles well separated and dispersed in the whole tube. Moreover, a further advantage of this filling technique is the possibility of controlling the nanoparticle size and then the magnetic properties of the composite material by choosing proper values of the initial salt solution concentration. This is very important in view of the promising applications of the $\mathrm{L}_{0} \mathrm{FePt}$ filled MWCNTs as magnetic tips for magnetic force microscopy. In this context, work is in progress aimed at filling just the terminal part of MWCNTs.

\section{Acknowledgments}

The UE Contract N. FP7-ICT-2007-2-224001 is acknowledged.

\section{References}

[1] Inomata K, Sawa T, Hashimoto S 1988 J. Appl. Phys., 64 (5) 2537.

[2] Sun S 2006 Adv. Mater. 18393

[3] Capobianchi A, Campi G, Camalli M, Veroli C 2009 Z. Kristallogr. 224384

[4] Capobianchi A, Colapietro M, Fiorani D,. Foglia S, Imperatori P, Laureti S, Palange E 2009 Chem. Mater. 212007

[5] Iijima S 1991 Nature 3546348.

[6] Chen J, Hamon M A, Hu H, Chen Y, Rao A M, Eklund P C, Haddon R C 1998 Science 28295

[7] Yao X, Wu C, Du A, Zou J, Zhu Z, Wang P, Cheng H, Smith S, Lu G 2007 J. Am. Chem. Soc. 12915650.

[8] Pan X, Fan Z, Chen W, Ding Y, Luo H, Bao X 2007 Nature Materials 6507. 
[9] Kamat P V 2007 J. Phys. Chem. C 1112834.

[10] Materials Today, special issue on "Nanowire and nanotubes: electronics and photonics in one dimension", 9, No. 10, October 2006.

[11] Wildgoose G G, Banks C E, Compton R G 2006 Small. 2182.

[12] Monthioux M, Flahaut E, Cleuziou J-P 2006 J Mater Res 212774.

[13] Terrones H, López-Urías F, Muñoz-Sandoval E, Rodríguez-Manzo J A, Zamudio A,

Elías A L 2006 Solid State Sciences 8303.

[14] Emerich D F, Thanos C G 2006 Biomolecular Engineering 23171.

[15] Capobianchi A, Foglia S, Imperatori P 2006 International patent application, No PCT/IT2006/000119.

[16] Capobianchi A, Foglia S, Imperatori P, Notargiacomo A, Giammatteo M, Del Buono T, Palange E 2007Carbon 452205.

[17] Capobianchi A, Foglia S, PalangeE, Arrizza L, Veroli C, Vasquez Mansilla M, Fiorani D 2009 Solid State Phenomena 151166

[18] Sun S, Murray C B, Weller D, Folks L, Moser A 2000 Science 2871989

[19] Saito Y, Yoshikawa T, Bandow S, Tomita M, Hayashi T 1993 Phys Rev B 481907. 


\section{Figures}

Figure 1. $\left[\mathrm{Fe}\left(\mathrm{H}_{2} \mathrm{O}\right)_{6}\right]\left[\mathrm{PtCl}_{6}\right]$ complex crystal packing showing the alternating $\mathrm{Fe}$ and $\mathrm{Pt}$ atomic planes.

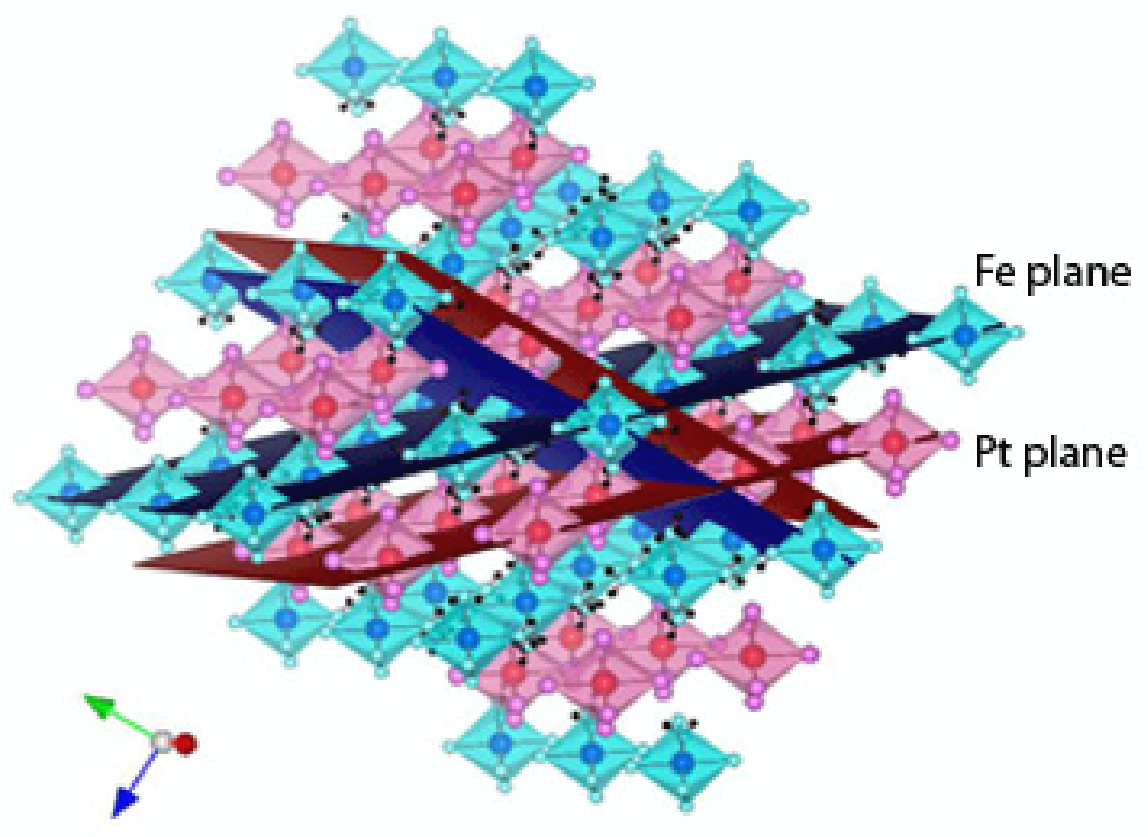

Figure 2. FePt@MWCNTs from 0.1M (left) and 0.01M (right) solution of $\left[\mathrm{Fe}\left(\mathrm{H}_{2} \mathrm{O}\right)_{6}\right]\left[\mathrm{PtCl}_{6}\right]$ complex. Bars are equal to $50 \mathrm{~nm}$ in both figures.

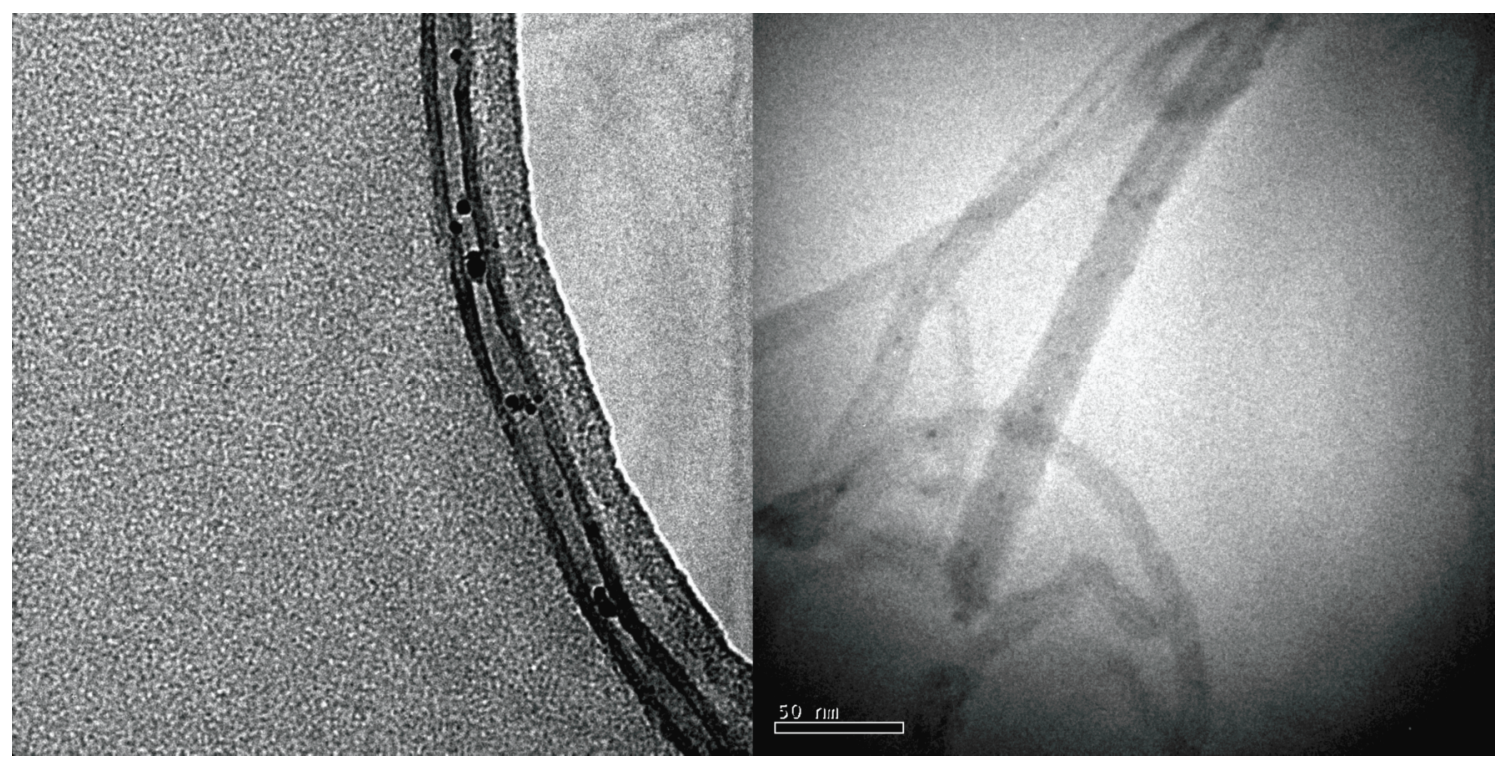


Figure 3. XRD patterns of FePt@MWCNTs; In the inset XRD pattern of open and empty MWCNTs is reported.

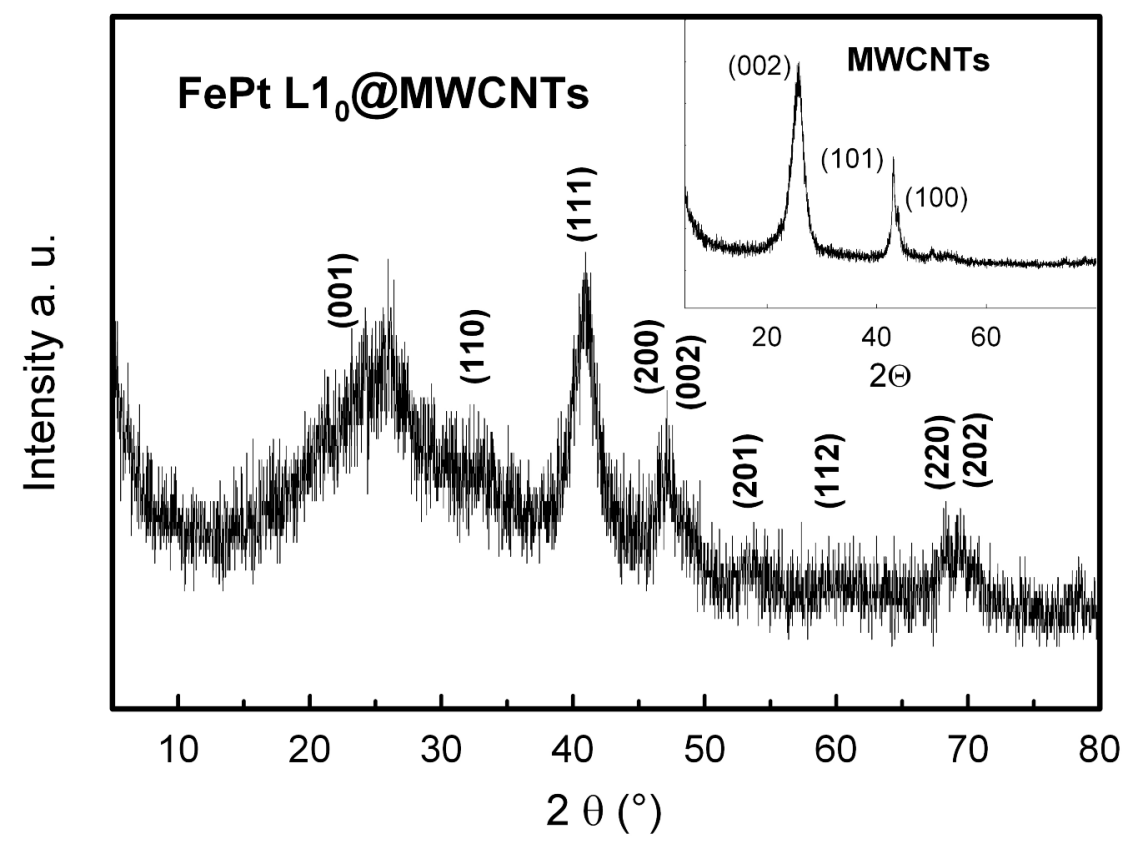

Figure 4. Low temperature hysteresis loop of open and empty MWCNTs.

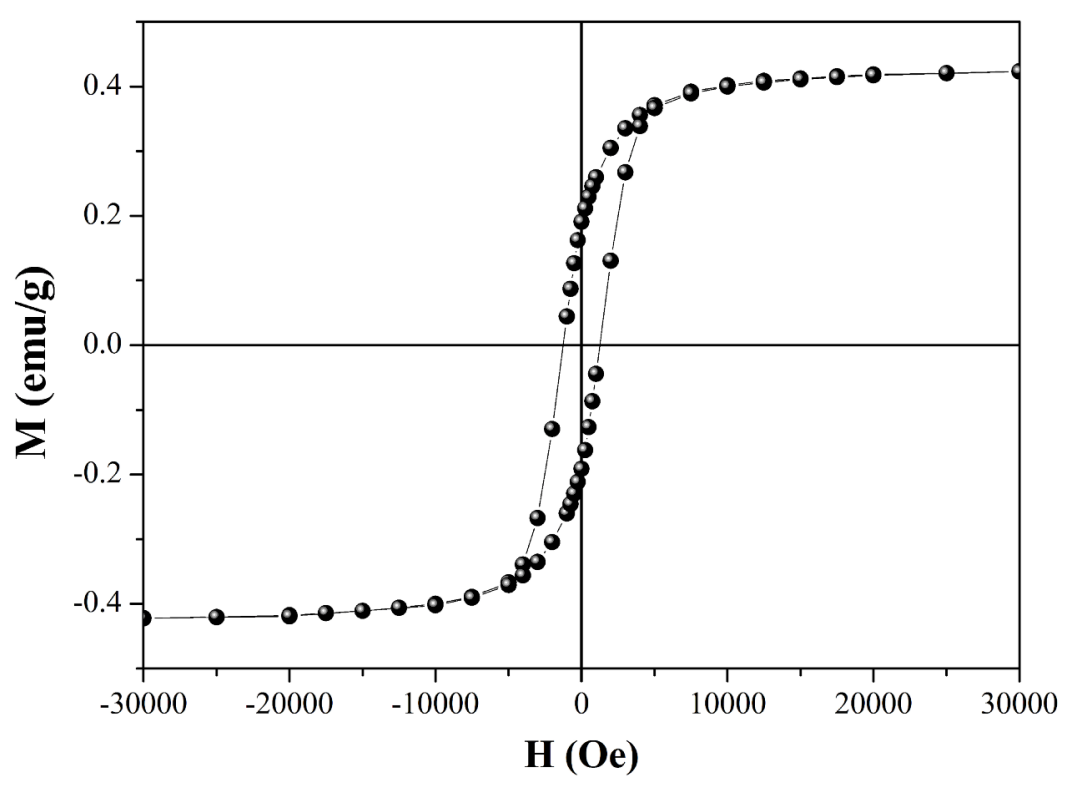


Figure 5. Hysteresis loop at $\mathrm{T}=5 \mathrm{~K}$ (closed circles) and $300 \mathrm{~K}$ (open circles) of the FePt@MWCNTs obtained from the $0.1 \mathrm{M}$ starting solution.

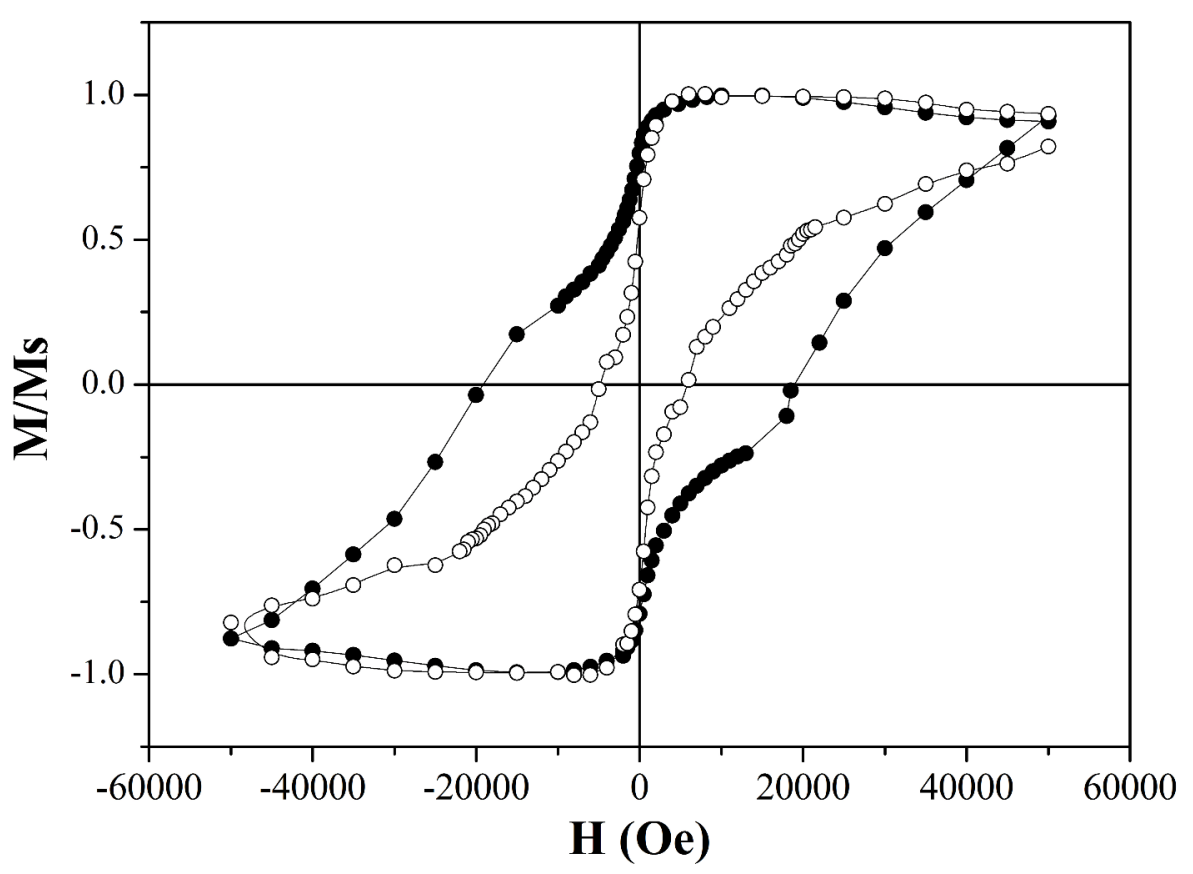

Figure 6. ZFC (lower curve) FC (upper curve) measurement $\left(\mathrm{H}_{\text {appl }}=100 \mathrm{Oe}\right)$ of FePt@MWCNTs sample obtained from $0.1 \mathrm{M}$ starting solution.

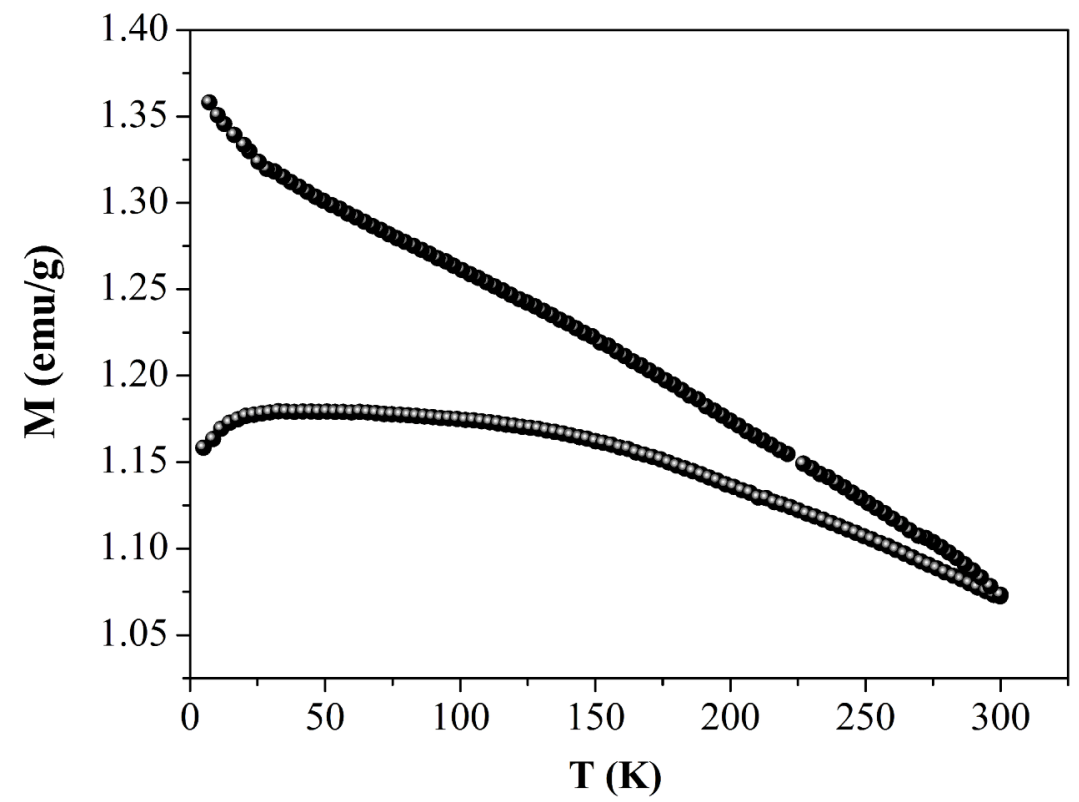


Figure 7: hysteresis loop at $\mathrm{T}=5 \mathrm{~K}$ (closed circles) and $300 \mathrm{~K}$ (open circles) of the FePt@MWCNTs sample obtained from the $0.01 \mathrm{M}$ starting solution.

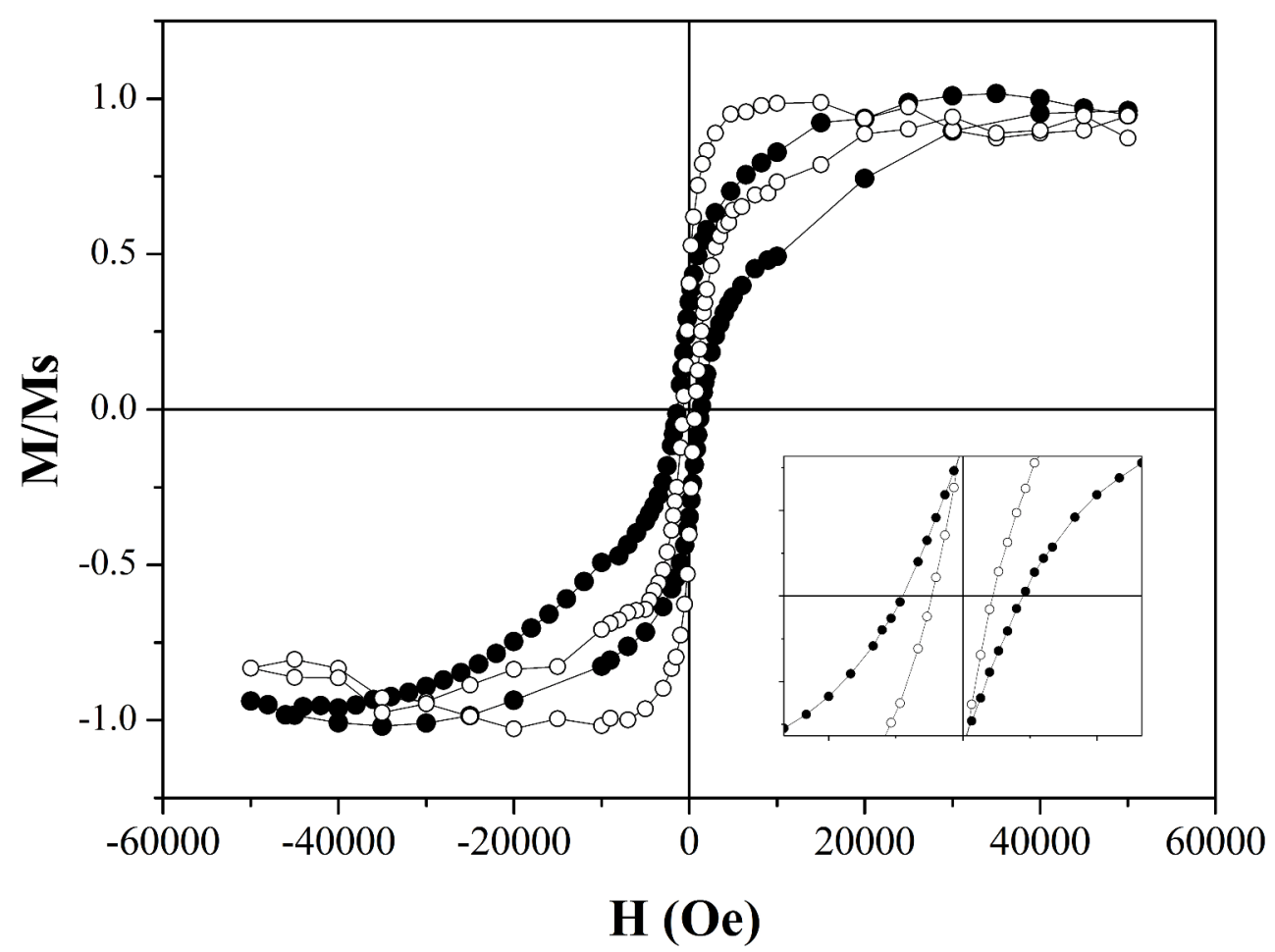

